Relations industrielles

Industrial Relations

\title{
Les relations humaines du travail
}

\section{Pie XII}

Volume 11, numéro 3, juin 1956

URI : https://id.erudit.org/iderudit/1022626ar

DOI : https://doi.org/10.7202/1022626ar

Aller au sommaire du numéro

Éditeur(s)

Département des relations industrielles de l’Université Laval

ISSN

0034-379X (imprimé)

1703-8138 (numérique)

Découvrir la revue

Citer ce document

XII, P. (1956). Les relations humaines du travail. Relations industrielles /

Industrial Relations, 11(3), 215-216. https://doi.org/10.7202/1022626ar

Tous droits réservés (C Département des relations industrielles de l’Université Laval, 1956
Ce document est protégé par la loi sur le droit d'auteur. L’utilisation des services d'Érudit (y compris la reproduction) est assujettie à sa politique d'utilisation que vous pouvez consulter en ligne.

https://apropos.erudit.org/fr/usagers/politique-dutilisation/ 
Monsieur l'abbé Pépin, conseiller moral des Centres d'Apprentissage, nous écrivait dernièrement:

«Vous avez toute mon admiration pour le travail de géant que vous avez déja réalisé. C'est ma conviction que cette réalisation professionnelle commencée au nom do la loi de l'Aide à l'Apprentissage devrait se poursuivre dans les mêmes conditions. 》

En plus des avantages d'ordre technique et professionnel, je crois devoir ajouter trois autres faits qui laissent percevoir toutes les possibilités de réalisation d'une profession qui s'occupe de la formation de ces membres. Je signalerai:

l-que, de 1952 à 1955, 619 persones, dont un bon nombre de contremaîtres et de surintendants, parfois des manufacturiers, ont pris part aux Soirées du Cuir oi des experts leur ont montré les développements les plus modernes de la machinerie, de loutillage et du matériel. C'est la plus excellente préparation pour faire face aux changements futurs;

2-Depuis dix ans, la Commission d'Apprentissage enseigne les termes français du métier, termes qui étaient à peu près complètement ignorés avant 1944. Aujourd'hui, il est très rare que nous recevions une lettre française où l'on n'emploie pas exclusivement les termes techniques français;

3-depuis dix ans également la Commission d'Apprentissage s'intéresse à la sécurité. La sécurité s'enseigne à l'école; une série de cours a été donnée dans les usines; les inspecteurs du comité sont intéressés à la sécurité; dans l'analyse de chaque opération, la sécurité est un point clé. Quel en est le résultat? En 1947, l'industrie payait à la Commission des Accidents du Travail .60 du $\$ 100.00$; en $1954, .15 \mathrm{du} \$ 100.00$. Cette diminution des prestations n'est qu'un aspect de la question; le point le plus important, c'est le nombre de personnes qui ont été protégées contre les accidents, et qui autrement seraient peut-être handicapés pour la vie.

J'ai assisté à la naissance et au développement de la Commission d'Apprentissage de la Chaussure et je connais les progrès merveilleux réalisés par d'autres commissions d'apprentissage. Je souhaite de tout coeur que, bientôt, tous les métiers et professions s'occuperont de la formation professionnelle de leurs membres; les résultats valent le travail qu'ils requièrent.

\section{LES RELATIONS HUMAINES DU TRAVAIL}

Nous ne savons pas à combien de reprises, le Souverain Pontife s'est exprimé sur la nature du travail et celle de l'entreprise. Aujourd'hui où partout l'on ne parle que de productivité, de rendement, d'organisation scientifique du travail, le pape a rappelé aux délégués de la Conférence internationale sur les relations humaines organisée par l'Agence européenne de productivité de L'O.E.C.E. les principes de l'Eglise sur ce sujet.

Après avoir constaté que la recherche scientifique dans le domaine technique abouti, en somme, à mettre en relief une donnée déjà depuis longtemps contenue dans l'enseignement de l'Eglise: l'importance des relations humaines dans le travail, il démontre que la productivité n'est pas une fin en soi et que chaque homme représente une valeur transcendante et absolue.

L'idée que l'on se fait de l'homme dans les relations du travail a une importance capitale pour l'Eglise, «tous les hommes sont égaux en dignité devant Dieu; ils doivent donc l'ètre aussi dans les rapports libres ou nécessaires qui les unissent.

«Or, la communauté de travail, qui de nos jours s'établit moralement sur la base des contrats entre les employeurs et les employés des grandes entreprises, 
constitue de la part des premiers un véritable engagement envers les seconds, car ils demandent à ceux-ci le meilleur de leur temps et de leurs forces. Ce n'est donc pas seulement un travailleur que l'on embauche et auquel on achète son travail; c'est un homme, un membre de la société humaine, qui vient collaborer au bien de cette même société dans l'industrie en question. Certes, une entreprise, même moderne, n'est pas totalitaire; elle n'accapare pas des initiatives qui, placées hors de son activité particulière, appartiennent personnellement aux travailleurs. En outre, une entreprise moderne ne se résout pas en un jeu de fonctions techniques coordonnées de façon anonyme. Elle unit par contrat des associés, dont les responsabilités sont différentes et hiérarchisées, mais auxquels le travail doit fournir le moyen d'accomplir toujours mieux leurs obligations morales, personnelles, familiales et sociales. Ils ont à se prêter loyalement un service mutuel, et si l'intérêt des employeurs est de traiter leurs employés en hommes, ils ne sauraient se contenter de considérations utilitaires: la productivité n'est pas une fin en soi. Chaque homme, au contraire, représente une valeur transcendante et absolue, car l'auteur de la nature humaine lui a donné une âme immortelle. Bien plus, il s'est fait homme et s'identifie moralement à quiconque attend d'autrui le supplément d'être qui lui manque: «Tout ce que vous ferez au plus petit de mes frères, c'est à moi que vous l'aurez fait ». (Matth. XXV, 40) Lui-même n'est pas venu pour être servi, mais pour servir (cf. Batth. XX, 28), et il n'a pas hésité à donner sa vie pour sauver les hommes. Voilà d'où vient l'éminente dignité de toute personne humaine et la responsabilité de quiconque emploie un homme à son service.» 